\title{
APRESENTAÇÃO À SEÇÃO TEMÁTICA ESCRITA DA PESQUISA
}

\author{
Universidade Federal do Rio Grande do Sul - UFRGS, Brasil \\ Jorge Ramos do Ó \\ Universidade de Lisboa - ULisboa, Portugal
}

Os caminhos da escrita da pesquisa constituem, junto com seu objeto em si, o elemento para o qual o pesquisador deve dirigir o melhor da sua atenção, uma vez que o trabalho de pesquisa, ainda mais num campo como o da Educação, não registra uma realidade que seria anterior ao próprio ato de pesquisar ou, de outro modo, a existência de um suporte independente dos instrumentos de que a investigação se serve para operar sua documentação.

$\mathrm{Na}$ gênese desta seção temática encontra-se o desígnio de reelaborar e fazer operar, a partir do seu enfrentamento, tanto os desafios quanto os impasses, tanto os bloqueios quanto as saídas ocasionais que envolvem a prática da escrita acadêmica no domínio da pesquisa em Educação. As diferentes perspectivas que aqui comparecem convergem para tensionar a proposição segundo a qual o pesquisador poderia ocupar o lugar de origem de um estilo e operar um saber conformado antes mesmo do próprio ato de escrever ter lugar. Os signatários dos textos tomam, desde logo, uma posição autorreflexiva acerca da natureza mesma do trabalho escritural. Deixam completamente de lado o postulado - em boa medida posto a circular na modernidade a partir das instituições educativas - do autor como um todopoderoso, figura que amiúde nos aparece como estando na origem de tudo quanto de extraordinário afirma. Aqui, o conjunto dos textos espelha, muito ao contrário, a assunção de uma herança plural e de vínculos teóricos explícitos, todavia não rígidos. Ele é tecido a partir desse chão móvel e movente, de uma comunidade que se vai forjando no pensamento partilhado, que se inicia da errância ou mesmo do êxodo de cada uma das investigações à frente apresentadas, com todos os riscos de desengano e desorientação metodológica que a entrega à aventura e ao jogo com o desconhecido sempre comporta.

Ao assumirem, à sua maneira, que trabalham para a reinscrição perpétua de uma linha de fronteira, estes pesquisadores querem nos devolver a possibilidade de compreendermos como a inventividade e o próprio ofício da pesquisa se engendram no e se alimentam do seu próprio estar-a-acontecer. Mostram-nos que o pensamento se produz muito mais no ato de experimentar do que no de interpretar. Defendem que o significado é uma construção ativa, dependente tanto da pragmática do contexto, do aqui e do agora, quanto de regras próprias dos regimes discursivos em que os autores se envolvem. Então, também aqui nós 
continuamos, enquanto investigadores, uma prática jamais inacabada de acumulação de perspetivas, de modelos, de ângulos, de pontos de vista. As paisagens sociais que se oferecem à imaginação e à análise do leitor não comportam mais a verdade de que a ciência fala através de um sujeito que se imagina soberano, mas, antes, a sua própria insegurança e provisoriedade. Está-se assim bem dentro da prática da produção da diferença que Lyotard (2003) traduziu por paralogia, quando a remeteu diretamente para as noções de sistema aberto, de covariação, de consenso local e de informação completa no momento considerado, de meta-argumentação finita e limitada. Nesse quadro, é como se as asserções de vocação globalizante fossem liminarmente bloqueadas e substituídas pelos jogos da vontade de potência de que tanto também nos falou Nietzsche.

É fato, ainda, que as várias posições teórico-metodológicas aqui presentes se baseiam em formas textuais e discursivas de análise, afirmando, desse modo, a força construtiva e constitutiva da linguagem. Ao mesmo tempo, cada artigo, à sua maneira, distingue-se do hábito, também ele incorporado na nossa tradição acadêmica, de produzir enunciados de ambição totalizante e que, em nome da verdade do conhecimento, visam a reforma e a mudança dos sistemas de ensino e de educação. Com efeito, já não há mais condições para sustentar a existência de enunciados cognitivos e denotativos que se tomem como de valor prático e de alcance geral. O trabalho científico espelha uma artesania da qual resultam análises parciais e localizadas, e não mais teses de vocação universalizante. Então, é como se escrever pudesse passar a ser o nome provisório que daríamos a uma prática intelectual que, incidindo sobre o legado do pensamento e da ciência, apenas se concretizaria quando efetivamente fôssemos capazes de consolidar um tipo de invenção local, específica, contingente. A imagem que aqui nos será predominantemente devolvida é, portanto, a de uma prática de escrita por intermédio da qual se intenta operar uma abertura no saber e, uma vez no seu interior, se vai descobrindo uma saída que há de engendrar, igualmente, o saber próximo. Trata-se de um exercício que, destarte, e no limite da sua ambição, quer convidar e desafiar o leitor a produzir a sua própria pesquisa, a se aventurar nos trabalhos e nas tarefas da escrita. A pesquisa torna-se útil não por ter o método científico ou o conceito certo, mas antes porque apresenta uma metodologia de trabalho teórico e empírico que, tornando manifestos os pressupostos sobre os quais ela mesma se constrói, permite, ato contínuo, a aparição de novas ideias e de novos enunciados.

Nas palavras deste coletivo ecoam de modo insistente ainda as posições teóricometodológicas de Deleuze. Este assumiu, uma e outra vez, que o seu trabalho se afastava de quaisquer predicados antropológicos. "Eu faço, refaço e desfaço os meus conceitos a partir de um horizonte móvel, de um centro sempre descentrado, de uma periferia sempre deslocada que os repete e diferencia" - confessou em Crítica e clínica. Para depois acrescentar: "a positividade do nosso tempo é a que nos faz crer num mundo em que "as individuações são impessoais" e "as singularidades pré-individuais" (Deleuze, 2000, p. 37-38). Nessas declarações se reafirma, a nosso ver, a grande hipótese de uma escrita inventiva, experimental, vocacionada para abeirar e tatear de fato o desconhecido. Deleuze exprimiuse nuns termos que identificam o desejo que acompanha a natureza do gesto coletivo desta seção temática: 
Ao escrevermos, como evitar que escrevamos sobre aquilo que não sabemos ou sabemos mal? É necessariamente neste ponto que imaginamos ter algo a dizer. Só escrevemos na extremidade do nosso próprio saber, nesta ponta extrema que separa o nosso saber e a nossa ignorância e que faz passar um no outro. É apenas deste modo que somos determinados a escrever. Suprir a ignorância é transferir a escrita para depois, ou antes, torná-la impossível. Talvez tenhamos aí, entre a escrita e a ignorância, uma relação ainda mais ameaçadora que a relação geralmente apontada entre a escrita e a morte, entre a escrita e o silêncio. Falamos, pois, de ciência, mas de uma maneira que, infelizmente, sentimos não ser científica (Deleuze, 2000, p. 38).

Outro ponto que coloca a trabalhar os investigadores reunidos nesta seção temática diz respeito ao questionamento acerca dos efeitos que o recorte do objeto de pesquisa produz sobre a forma de registro que o estudo assume. O que está em causa é problematizar o divórcio entre a trama da escrita e o conteúdo que ela veicula. Interessa produzir os argumentos que explicitem a relação inextricável entre escrita e objeto da pesquisa, o que pode nos levar a estender as fronteiras das formas canônicas do texto acadêmico para dar lugar a produção de objetos de investigação que não poderiam ser produzidos no interior dos figurinos habituais e hegemônicos da maquinaria da escrita acadêmica. Interessa-nos que a reflexão incida sobre as políticas do texto nas instituições de saber, indagando seus efeitos sobre as condições de produzir, com a pesquisa, novos modos de pensar não apenas dentro mas também no seu exterior.

Igualmente, o fazer-junto constitui ponto de reflexão desta seção temática. Os trabalhos apresentados refletem a necessidade pungente de uma reflexão acerca do trabalho de orientação, acerca da importância das relações estabelecidas no interior da comunidade acadêmica e do tipo de diálogo que aí se origina. Dão conta de um espaço pedagógico constituído por pequenos grupos de estudantes em torno de um professor, estruturalmente associado ao processo da pesquisa a partir de uma perspectiva analítica e metodológica particular. Trata-se de uma velha prática acadêmica que se caracteriza pela socialização de textos - sua análise e discussão, apropriação e produção - e por se centrar mais na realização dos trabalhos escritos intermédios de cada um dos seus participantes do que, propriamente, num produto final individualizado, embora estabeleça como seu horizonte a construção de uma dissertação ou tese. São, com efeito, vários os textos que tematizam o coração da instituição acadêmica na relação pedagógica entre orientando e orientador e dos estudantes entre si, para os descobrir enquanto iguais na busca de um saber por vir. Como se, naquela situação tão concreta e tornada banal pelo processo da repetição - não raras vezes semanal dos grupos de orientação e dos seminários da pós-graduação, se consumasse afinal um grande e velho princípio existencial, ético e político da própria cultura ocidental que é preciso reatualizar sempre: que é pela constante articulação da palavra oral com a palavra escrita que todos estão a ser convidados, e se convidam de facto, a fazer parte do movimento de produção do discurso e da construção do sentido. Aí nesse território da partilha e do diálogo, os participantes convidam-se mutuamente não apenas a viver, mas a participar na composição 
da vida, trabalhando com afinco nessa elipse que os conduzirá ao incógnito a partir de necessidades e problemas que se originam no interior de si mesmos.

Numa palavra, o traço marcante que atravessa os materiais que apresentamos é a autoimanência do discurso sobre as regras que o possam validar, como se a legitimidade do saber adviesse, em primeira linha, do que ele faz operar, da sua própria performatividade. E o mais desafiante de tudo isso é que o desenvolvimento do saber pode aqui corresponder tanto a um desdobramento inesperado, a um novo lance do argumento, como à invenção de novas regras, ou seja, a uma mudança do próprio jogo. Não se trata, portanto, de produzir o conhecido, mas o próprio desconhecido da pesquisa.

$$
* * *
$$

Patricia Peterle, em "O corpo a corpo da e na escrita", dá a mão à poesia e à crítica literária que dela se ocupa para pensar as condições de transformação do olhar do pesquisador sobre seu objeto. $\mathrm{O}$ artigo discute a escrita da pesquisa partindo do operar da função poética da linguagem que trabalha na direção de desativar suas funções pragmáticas, comunicativas, informativas e, nessa tarefa, abre espaço para novos rearranjos e combinações, permitindo que o novo tenha lugar. Ao transitar pela poesia, a autora sustenta que a voz do pesquisador só pode ser escutada em uma epistemologia da parcialidade, na qual está em causa não somente uma operação da língua, mas na língua, não só do pensamento, mas no pensamento. Um pensamento que a escrita não apenas documenta, mas, sobretudo, engendra.

Também em "Do letramento à escrita inventiva na universidade: potência transformadora da linguagem”, de Elaine Milmann, Cláudia Berchara Fröhlich e Janniny G. Kierniew, a interrogação sobre os meandros da escrita da pesquisa na universidade tramita de mãos dadas com uma reflexão sobre a função poética da linguagem. $\mathrm{O}$ artigo toma como campo de proveniência das questões que movimenta a experiência de uma das autoras em dois diferentes grupos de pesquisa - um no Instituto de Educação da Universidade de Lisboa e outro na Universidade Federal do Rio Grande do Sul (NUPPEC). Ambos os espaços orientam-se pela premissa de que a escrita da pesquisa é um evento de linguagem que cria/afeta o objeto de investigação, assim como a própria língua. Para desdobrar essa aposta, as autoras retomam autores da crítica literária e poetas brasileiros, em sua maioria artistas que têm sua produção assentada no terreno da poesia concreta. $\mathrm{O}$ trabalho da poesia sobre a língua é inspiração para constituir um lugar de indagação sobre os meandros da escrita acadêmica.

No artigo "O investigador libertino e a infância como indeterminado: a escrita científica enquanto ethos inventivo em duas propostas de autorreflexão e desterritorialização do sujeito escolar", seus autores, Tomás Vallera e Tiago Almeida, convidam o leitor a tomar parte de seu grupo de pesquisa. Numa escrita que coloca a conversar dois projetos de investigação, ainda em seu andamento, os pesquisadores refletem sobre e performam a hipótese de que a conversa sobre o tema de uma tese é "inseparável da discussão sobre a construção de seu objeto". Aquilo sobre o que um texto discorre é proposto como inseparável do modo como esse escrito é tecido. São acionadas duas imagens ao longo do artigo. Primeiro, a figura do 
libertino, que dá contornos a um percurso de pesquisa que se faz sustentado em um desejo de escrever aberto às inflexões que o próprio percurso inscreve. O investigador libertino pretende alcançar a escrita em uma posição em que emerja como fruto de uma relação especular com o objeto de pesquisa e, nessa medida, possa abrir-se aos descaminhos que esse objeto aporta aos a priori que por ventura venha a ter de carregar consigo. Uma segunda imagem posta a conversar é a da condição indeterminada da infância. $\mathrm{O}$ indeterminado aqui funciona quase como um convite a que o pesquisador que se ocupa do sujeito escolar possa, ele mesmo, experimentar essa condição, deslocando-se de si e de seus preconceitos como forma de fazer falar o ainda não dito. Ambas as imagens acionadas como tema de pesquisa funcionam, por meio de uma dobra, como guias metodológicos que dão forma ao caminho de investigação em curso.

A linguagem, proposta na posição, a um só tempo, de dar forma ao objeto de investigação, ao descobri-lo, e de construí-lo, ao desvelá-lo, orienta a discussão proposta por António Henriques em "A grande travessia: textos académicos para gente do risco e do movimento ousado". Sua indicação do texto como espaço metodológico situa em primeiro plano uma reflexão acerca dos caminhos da escrita da pesquisa como percursos decisivos no campo das ciências humanas. O que aqui está em causa é a construção de condições para que o estudante/pesquisador possa desaparecer na escrita, de forma a que esta possa aparecer nele e, no processo mesmo dessa aparição, se desenhem os contornos do próprio objeto, abrindose desse modo um espaço real para a surpresa, para a alegria de uma surpresa. Na tessitura dos fragmentos de textos e de cenas, o estudante/pesquisador pode experimentar a emergência de um traço singular que inscreve uma nova maneira de dizer o mundo, pois se os fragmentos que utiliza são seus conhecidos, porque por si recolhidos, não o é a forma em que serão costurados e a imagem que dessa costura há de redundar. A essa imagem só se chega ao final da pesquisa, e é preciso conservá-la numa temporalidade regida pelo só-depois, para que a "escrita permaneça o motor da investigação e uma promessa infinita".

No caminho da pesquisa, entre a antecipação de um percurso e a localização de um ponto de chegada, o mais das vezes inscrito por ordenadores exteriores, na própria investigação como o prazo que finda -, podem emergir ciscos, pedras, fracassos, necessidade de construir desvios... Diante desses aparentes infortúnios, o pesquisador pode aferrar-se à sua construção antecipada, ao custo de tornar-se cego aos corpos estranhos à linha planejada, ou pode, na inversa e mesmo experimentando certo vacilo, dar seguimento ao trabalho percorrendo um trecho nas sombras como quem é acometido de certa miopia em relação ao objeto de pesquisa que busca contornar. Flavia Trocoli, no artigo "Clarice Lispector, Hélène Cixous e a miopia do procedimento", convida-nos a testemunhar o efeito da leitura que Cixous faz de Clarice: a fabricação de um modo de ler pelo detalhe. O trabalho em torno do conto "A legião estrangeira" alça a miopia ao patamar de operador de um procedimento de pesquisa que pode interessar ao campo das Ciências Humanas; um procedimento que pode nos colocar em um caminho que, partir das escuridões "e não a despeito delas, erga um novo dia, um novo mundo, quem sabe".

$\mathrm{Na}$ radicalidade da suspensão de uma antecipação, talvez justo nesse ponto possamos situar os efeitos da pandemia de COVID-19: um mundo que se estabelecia pela reiteração do 
mesmo e que mensurava seus desvios, suas diferenças, a partir daquilo que essa reiteração inscrevia, viu-se em absoluta suspensão. Os modos de viver, circular e encontrar-se com o outro foram surrupiados do cotidiano. Outros modos precisaram - e seguem demandando ser construídos. Novas perguntas se colocaram, novas respostas estão por ser elaboradas. No artigo "Do Mconf ao Vale do Mconf: topografias poéticas em um sistema de webconferência em meio à pandemia", Luciano Bedin da Costa e Anna Letícia Ventre tomam essa cambalhota imposta à vida como instigação para uma reflexão sobre os caminhos das aprendizagens nos territórios virtuais. Inicialmente guiados pela noção de sursis acionada por Sartre em Caminhos da liberdade (1976), noção que dá contorno, a partir do pensamento jurídico, a uma suspensão cuja duração se desconhece, os autores refletem sobre - e com uma experiência de seminário na pós-graduação, derivando dessa experiência em ambiente virtual uma potente elaboração sobre os meandros da noção de presença e sua relação com as aprendizagens. Nos caminhos dessa análise o leitor se verá acompanhado por um convite a tecer as pontes entre criação poética e o compromisso ético-político da academia.

É também a partir de suas experiências e experimentações como docentes da pósgraduação, na tessitura próxima com os/as estudantes de uma disciplina que acolhem o desafio de uma escrita da qual não se demanda uma adesão às formatações características dos modelos acadêmicos hegemônicos, que Marcia Cavalcanti Raposo Lopes e Luiz Antonio Saléh Amado conduzem o leitor de "Experimentações da formação do EducadorPesquisador: práticas de pesquisa e escrita acadêmica a um trabalho com o pensamento" na busca por alargar o espaço para a invenção na produção do saber científico. Nesse artigo, a escrita acadêmica, pensada a partir de um tensionamento entre um trabalho guiado pela recognição e um caminho que busca dar lugar à invenção, é tomada como território privilegiado em que se pode incidir de forma a abrir pequenas frestas capazes de abrigar outros modos de pensar, outras sensibilidades, criando um espaço em que se dê abrigo a um exercício desejante de pesquisa, o que tem por consequência, vislumbra-se, a extensão das fronteiras e do próprio alcance das políticas do texto na academia. O trabalho de promoção dessa extensão toma o caminho da análise da implicação do desejo de pesquisador nos desdobramentos que a pesquisa assume.

A análise de implicação como ferramenta para pensar a função normativa presente na prática da escrita da pesquisa no campo da Educação constitui o fio condutor do artigo "Implicações, desassossegos e criação na escrita acadêmica", de Estela Scheinvar, Katia Aguiar e Maria Lívia do Nascimento. O artigo convida a problematizar as mecânicas do governo da escrita, que são também mecânicas do governo do pensar, por meio da análise de implicação, potente ferramenta de estranhamento aos modelos hegemônicos de produção escrita, fazendo com que esta se aproxime dos seus limites e limiares. Seu convite é acolher a provocação de Deleuze (1988, p. 10) para que possamos só escrever "na extremidade de nosso saber, nesta ponta extrema que separa o nosso saber e nossa ignorância e que transforma um no outro". Ao tocar nesse ponto, as autoras explicitam também o mote teóricometodológico desta seção temática no seu conjunto.

De algum modo, Ana Luíza Paz, em "A escrita da tese à procura da investigação sobre a vida: uma autoetnografia dos processos de apropriação e ensino da escrita acadêmica", 
realiza o que ambos os trabalhos anteriores indicam. Por meio de um estudo autoetnográfico, a autora revisita os caminhos de escrita de sua tese sobre ensino da música em História da Educação, conduzindo o leitor a uma reflexão sobre os impasses e as escolhas experimentadas no processo de criação. $\mathrm{O}$ artigo, partindo de uma reflexão sobre a experiência singular de escrita, conquista territórios de reflexão onde a pessoalidade se rende aos traços presentes em um campo que pode ser reconhecido como coletivo. A indicação da constituição de uma comunidade de aprendizagem no espaço de orientação em grupo estabelece os contornos de um território capaz de propiciar o estabelecimento de transferências horizontais de trabalho; trata-se de um elemento precioso do exame que a autora faz de seus próprios caminhos de escrita na academia.

O tema do endereçamento ao outro que nos traz o artigo de Ana Luíza Paz, pela mobilização da comunidade de aprendizagem que pode representar o grupo de orientação, aparece nos próximos dois artigos em uma dobra que materializa o lugar das correspondências no processo de pesquisa no campo da Educação. A colocação em causa da produção escrita por meio de missivas coloca em cena o jogo da alteridade levando-o o mais longe possível. A presença do outro na ideação e composição que dele fazemos por meio da escrita abre um espaço para que a nossa própria escrita - e o pensamento - possa se arriscar por territórios que de outra forma não se arriscaria. A presença de um dialogismo transformador que fertiliza a escrita como arte de vida, e que figura como bússola da convocação ao pensamento, são-nos de novo trazidos por Elisandro Rodrigues e Betina Schuler no texto "A pele da escrita acadêmica em educação: o exercício epistolar como uma conversação". No artigo, os autores levam o leitor a se perguntar o quanto "uma escrita acadêmica em educação poderia operar como uma carta que convida ao diálogo, ao pensamento compartilhado, uma abertura a outros mundos".

Também no artigo de Bruna Moraes Battistelli e Érika Cecília Soares Oliveira, "Cartas: um exercício de cumplicidade subversiva para a escrita acadêmica", o trabalho sustentado nas correspondências ganha fôlego ao pensar os processos de escrita na/da pesquisa nas humanidades. Esse artigo propõe o trabalho de pesquisa como um fazer cartagráfico, sustentando esse neologismo no tripé da escrita, da pesquisa e do cuidado. As autoras, dessa forma, abrem espaço para que se pense o pesquisar articulado pela preposição $\mathrm{com}$ - enlace que tensiona e sobrepõe a preposição sobre, guia tão comum no território da pesquisa. Esse deslocamento - do sobre ao com - situa os processos da pesquisa num obrar que se faz com os sujeitos que ela envolve por meio do acolhimento a suas letras depositadas em correspondências. As cartas são propostas nesse artigo como uma via para constituir um espaço de pesquisa capaz de acolher o protagonismo dos sujeitos que, desde seus territórios existenciais, são portadores de um saber sobre a vida, trabalhando no sentido de descolonizar as políticas de pesquisa na academia.

Diante das políticas hegemônicas da pesquisa na academia, Facundo Giuliano, no artigo "Caminitos al margen del mundo avaluador: passajes metodológicos de uma crítica de la razón avaluadora", propõe que mobilizemos, inspirados no trabalho de Rancière (2012), a dimensão do indisciplinar, que tomemos a via de uma pesquisa indisciplinada, melhor dito, que transitemos em um caminho aberto a nos deixar afetar por aquilo que acontece. Nesse 
texto, rico em imagens, o autor propõe que reflitamos acerca dos efeitos aprisionantes da "razón evaluadora" sobre os desdobramentos da escrita da pesquisa em Educação, especialmente no que tange à resistência relativa à emergência de um pensamento novo que esse modo de operar a validação de um trabalho produz. Uma resistência que, o mais das vezes, estreita a possibilidade de que um caminho ainda não trilhado tenha lugar, de que um encontro cuja afetação ainda não mapeada se dê. O artigo, tecido sob a forma de um ensaio, mobiliza autores em uma trama que permite questionar os caminhos hegemônicos da pesquisa que acabam por demitir o sujeito da escrita e, com ele, dispensar da cena tanto a subjetividade quanto a alteridade.

O ensaio também é a forma que toma o artigo de Eulàlia Collelldemont Pujadas e Anna Gómez Mundó, "Comprender y escribir lo difícil: relatar perdiéndose en lo conflictivo de la educación". Nele as autoras convidam o leitor a refletir sobre as formas de escrever o complexo, o feio, o oculto, o belo sem perder de vista o laço indissociável entre metodologia, epistemologia, ética, política na pesquisa em história da educação. O desafio encontra-se em transmitir o conhecimento histórico articulado em um pensamento, a um só tempo, rigoroso e livre, preciso mas aberto em simultâneo à produção de novos sentidos, a dimensões do conhecimento não antevistas pelo pesquisador. As autoras propõem o ensaio como forma narrativa capaz de guardar lugar para a dúvida, o descontínuo e mesmo o vazio, tão necessários a que aquilo que se apresenta como complexo no campo da pesquisa em educação ganhe escritura.

Finaliza esta seção temática o artigo de seus organizadores. Simone Moschen e Jorge Ramos do Ó, em "A escrita da pesquisa: uma conversa a partir de Freud, Lacan e Foucault", estabelecem uma conversa em torno do tema da escrita, convidando para o diálogo Freud, Lacan e Foucault. Na trama da conversa, a escrita da pesquisa é proposta como uma prática de si de cujo exercício mesmo resulta o pesquisador como efeito desse obrar. O escrever é delineado a partir de uma posição em que o pesquisador, ao ensaiar-se na escrita, ensaia e constrói a própria pesquisa da qual pode resultar um alargamento das formas de nomear o mundo, bem como aberturas para um porvir em que novos modos de existir tenham lugar e possam ser transmitidos aos que chegam. O tempo da pesquisa não é o das antecipações, mas aquele em que algo decanta e acaba por produzir como efeito a sensação de que sempre esteve ali. É na medida em que a escrita da pesquisa não espelha um mundo que lhe antecede, que ingressa no debate o tema da ética e da responsabilidade dos pesquisadores pelos mundos que sua investigação constitui. Responsabilidade que não convoca um indivíduo isolado, todo-poderoso, dono dos caminhos que percorre, mas um sujeito que, na tessitura com seus próximos, a comunidade de pesquisadores da qual faz parte - grupo de orientação, laboratórios de investigação e redes de pesquisadores -, assume a posição de dar consequência ao que sua escrita cifra.

\section{Referências}

DELEUZE, G. Crítica e clínica. Lisboa: Edições Século XXI, 2000. 
DELEUZE, G.; PARNET, C. Diálogos. São Paulo: Escuta, 1998.

LYOTARD, J. A condição pós-moderna. Lisboa: Gradiva, 2003.

RANCIERE, J. Pensar entre disciplinas. In: FRIGERIO, G.; DIKER, G. (Org.) Educar: (sobre)impressiones estéticas. Buenos Aires: Del estante, 2012. p. 283-291.

SARTRE, J.-P. Os caminhos da liberdade II - Sursis. São Paulo: Círculo do Lívro, 1976.

\section{Correspondência}

Simone Zanon Moschen: Psicanalista, membro da Associação Psicanalítica de Porto Alegre, professora titular do Instituto de Psicologia - UFRGS - e dos Programas de Pós-graduação em Educação e em Psicanálise: Clínica e Cultura, ambos da UFRGS. Coordenadora do NUPPEC/UFRGS - Eixo Psicanálise, Educação e Cultura. Membro da Rede de Pesquisa Graphias. Bolsista Produtividade CNPq.

E-mail: simoschen@gmail.com

Jorge Manuel Nunes Ramos do Ó: Professor Associado com agregação do Instituto de Educação da Universidade de Lisboa. Tem trabalhado com temáticas relacionadas com história da educação e da cultura, educação artística, análise do discurso e pedagogia do ensino superior, em especial sobre os processos de escrita académica.

E-mail: jorge.o@ie.ulisboa.pt

Texto publicado em Currículo sem Fronteiras com autorização dos autores. 